\section{Index case of kite string causing neurovascular and tendon injury to ankle is being reported}

Sir,

Kite-flying is a popular activity in children and young adults in North India in the months of June, July, August and September. ${ }^{[1]}$ Kites are associated with various types of injuries including accidents that occur during the preparation of the threads, electrical injuries from high-tension currents, falls from heights that occur during the game, injuries caused to bystanders during kite flying, especially those riding motorcycles or bicycles. ${ }^{[2-4]}$

Among published cases of kite string injuries, majority are head and neck injuries. However, kite string injuries most commonly involve palm and fingers. There are some reports of injuries to the other parts of the body particularly lower limbs, but in those cases, it was due to electrical burn. ${ }^{[5]}$ Here, we report a case of injury to ankle leading to transection of nerves, vessels and tendons.

A 70-year-old male was walking on the road during the evening hours, and suddenly his left leg got entrapped in a kite string which was entangled around the fence of a park on one side and a vehicle on the other side. When he tried to pull his leg out of the string, there

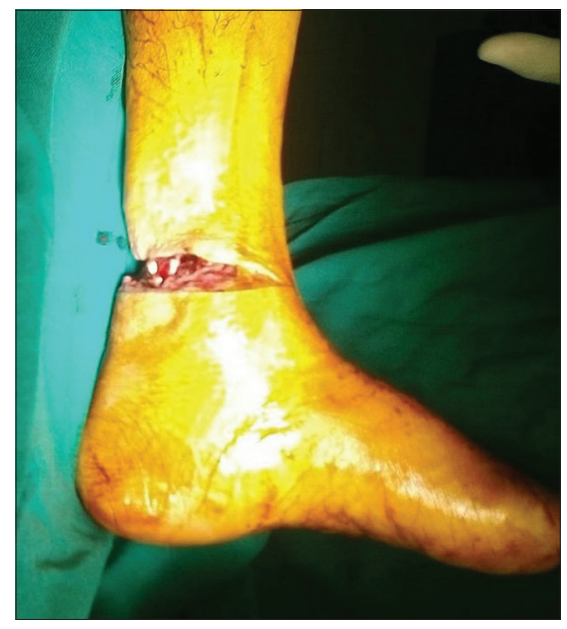

Figure 1: Kite string injury to ankle was severe pain and heavy bleed. On exploration under anaesthesia and tourniquet control, there was complete transection of all structures of the posterior compartment (tendoachilles, tibialis posterior, posterior tibial artery and posterior tibial nerve) and lateral compartment (peroneus longus, peroneus brevis, flexor hallucis longus and peroneal artery) [Figure 1]. Only $4 \mathrm{~cm}$ strip of skin in the anterior aspect, anterior compartment structures and bones were not injured. All the injured structures were repaired. The patient had an uneventful recovery of the wound but had prolonged stiffness of ankle joint.

A processed thick thread or, occasionally, a thin metal wire is used to fly the kite. Previously, kite flyers mainly used a string that was made with 3-9 layers of variously treated cotton thread. Later on, elastic string and nylon cord were introduced. To make the competition more challenging, kite fighters started using metallic, chemical and glass powder (from fused bulbs and fluorescent glass tubes) coated string (manja), in the recent past. This made the simple traditional fun of kite flying deadlier, and now, it has become the potential cause of severe injury, disability and death each year. ${ }^{[5]}$

\section{Financial support and sponsorship}

Nil.

\section{Conflicts of interest}

There are no conflicts of interest.

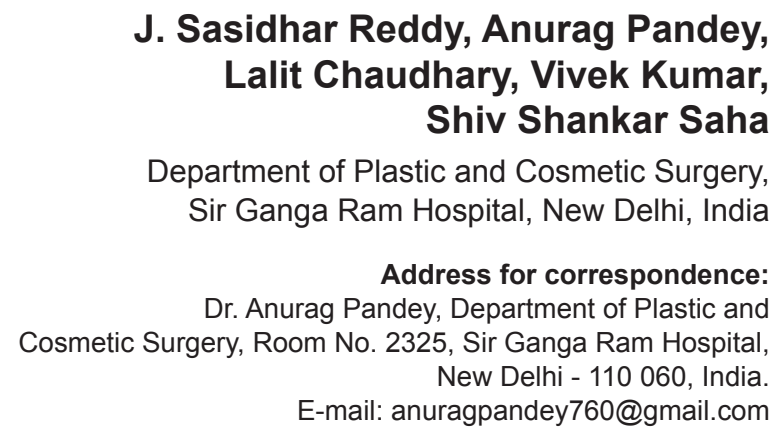

\section{REFERENCES}

1. Tiwari VK, Sharma D. Kite-flying: A unique but dangerous mode of electrical injury in children. Burns 1999;25:537-9.

2. Patil SB, Khare NA, Jaiswal S, Jain A, Chitranshi A, Math M. Changing patterns in electrical burn injuries in a developing country: Should prevention programs focus on the rural 
population? J Burn Care Res 2010;31:931-4.

3. Kyriacou DN, Zigman A, Sapien R, Stanitsas A. Eleven-year-old male with high-voltage electrical injury and premature ventricular contractions. J Emerg Med 1996;14:591-7.

4. Wankhede AG, Sariya DR. An electrocution by metal kite line. Forensic Sci Int 2006;163:141-3.

5. Wankhede AG, Sariya DR. "Manja" - A dangerous thread. J Forensic Leg Med 2008;15:189-92.
This is an open access article distributed under the terms of the Creative Commons Attribution-NonCommercial-ShareAlike 3.0 License, which allows others to remix, tweak, and build upon the work non-commercially, as long as the author is credited and the new creations are licensed under the identical terms.

\begin{tabular}{|l|l|}
\multicolumn{3}{c|}{ Access this article online } \\
\hline Quick Response Code: & Website: \\
\hline
\end{tabular}

How to cite this article: Reddy JS, Pandey A, Chaudhary L, Kumar V, Saha SS. Index case of kite string causing neurovascular and tendon injury to ankle is being reported. Indian J Plast Surg 2016;49:132-3. 